Bài báo khoa hoc

\title{
Phân tích các yếu tố ảnh hưởng đến thay đổi diện tích cù lao Long Khánh, huyện Hồng Ngự, tỉnh Đồng Tháp
}

\author{
Lê Hoàng Tú ${ }^{1}$, Đinh Văn Duy ${ }^{2 *}$, Lê Hải Trín ${ }^{2}$ Nguyễn Thái An², Huỳnh Vương Thu \\ $M_{i n h}{ }^{3}$, Huỳnh Thị Cẩm Hồng ${ }^{2}$, Trần Văn Tý2 \\ ${ }^{1}$ Sở Nông nghiệp \& Phát triển Nông thôn tỉnh Đồng Tháp; tucctldt@gmail.com. \\ ${ }^{2}$ Khoa Công nghệ, Trường Đại học Cần Tho; dvduy@ctu.edu.vn; lehaitri@gmail.com; \\ anb1908310@student.ctu.edu.vn; htchong@ctu.edu.vn; tvty@ctu.edu.vn. \\ ${ }^{3}$ Khoa Môi trường \& Tài nguyên Thiên nhiên, Trường Đại học Cần Thơ; \\ hvtminh@ctu.edu.vn. \\ *Tác giả liên hệ: dvduy@ctu.edu.vn; Tel.: +84-906975999.
}

Ban Biên tập nhận bài: 13/8/2021; Ngày phản biện xong: 8/9/2021; Ngày đăng bài: $25 / 12 / 2021$

Tóm tắt: Mục tiêu của nghiên cứu này là sử dụng ảnh viễn thám để quan sát sự thay đổi diện tích và vị trí của cù lao Long Khánh, huyện Hồng Ngự, tỉnh Đồng Tháp dựa theo phân tích các yếu tố ảnh hưởng như hàm lượng bùn cát lơ lửng $(\mathrm{SSC})$, lưu lượng dòng chảy $(\mathrm{Q})$ và vận tốc dòng chảy $(\mathrm{V})$ thông qua đo đạc thực tế. Ảnh Landsat 5,8 và Sentinel-2 được sử dụng để phân tích hiện trạng thay đổi đường bờ và diện tích bề mặt $(\mathrm{A})$ của cù lao giai đoạn 2000-2021. Các số liệu thứ cấp về hàm lượng bùn cát và lưu lượng dòng chảy được phân tích để tìm mối tương quan giữa các đại lượng này đến sự thay đổi diện tích bề mặt cù lao. Vận tốc dòng chảy đo đạc được so sánh với vận tốc không xói $\left(\mathrm{V}_{\mathrm{kx}}\right)$ của bùn cát cấu tạo bờ sông. Các kết quả phân tích cho thấy các yếu tố hàm lượng bùn cát lơ lửng, lưu lượng và vận tốc dòng chảy đều ảnh hưởng đến sự thay đổi diện tích cù lao. Tại đầu cù lao, vận tốc dòng chảy đang gây ra xói lở. Hiện nay, có rất ít các nghiên cứu về tương quan giữa các yếu tố thủy lực, thủy văn đến sự biến động diện tích của các cù lao ở Đồng bằng sông Cửu Long (ĐBSCL). Do đó, kết quả nghiên cứu này sẽ góp phần bổ sung một phần kiến thức về các yếu tố ảnh hưởng đến sự biến động của các cù lao trên các hệ thống sông của ĐBSCL.

Từ khóa: Cù lao Long Khánh; Đường bờ; Ảnh Landsat; Bùn cát lơ lửng; Lưu lượng; Vận tốc dòng chảy.

\section{Mở đầu}

Đồng bằng sông Cửu Long (ĐBSCL) là điểm cuối trong hành trình của dòng Mê Kông trước khi đổ ra biển thông qua hệ thống sông Tiền và sông Hậu [1] với rất nhiều cù lao (bãi giữa) dọc theo sông. Thông thường, các đoạn sông nơi xuất hiện các cù lao có hình dáng phình rộng ở giữa và co hẹp lại ở hai đầu cù lao, giống hình dáng dạ dày [2]. Cù lao là các vùng đất giữa sông được bồi đắp liên tục bằng trầm tích sông nên rất màu mỡ và đóng góp đáng kể cho sự phát triển kinh tế của các địa phương thông qua các ngành nghề như trồng trọt, thủy sản, du lịch sinh thái. Trong những năm gần đây, dưới tác động của thay đổi dòng chảy do biến đổi khí hậu $(\mathrm{BĐKH})$ và việc xây dựng các đập thượng nguồn, sạt lở nghiêm trọng đang xảy ra trên các cù lao trên hai hệ thống sông Tiền và sông Hậu.

Trên thế giới đã có nhiều nghiên cứu về cù lao trên sông với nhiều cách tiếp cận khác nhau như phân loại hình dạng các cù lao trên sông và tìm ra mối quan hệ giữa việc hình thành 
các cù lao với các quá trình thủy động lực học trong sông và trên lưu vực sông [3]. Mô hình số được áp dụng để tính toán tác động của sự thay đổi hình thái cù lao trên sông đến thay đổi đường bờ sông đoạn chảy qua cù lao [4]. Công nghệ viễn thám cũng được áp dụng để phân tích diễn biến diện tích cù lao trên sông nhằm đề ra các giải pháp quản lý bền vững cho các vùng đất cù lao trên sông Dương Tử [5].

Mặc dù các cù lao có ảnh hưởng đến hầu hết mọi khía cạnh của hệ sinh thái sông [6], các nghiên cứu về cù lao trên sông ở khu vực ĐBSCL còn rất hạn chế. Hầu hết các nghiên cứu trước đây chỉ tập trung phân tích sạt lở bờ sông và cù lao chỉ được nhắc đến như một phần trong các nghiên cứu về sạt lở bờ sông trên hai hệ thống sông chính là sông Tiền và sông Hậu, như nghiên cứu ứng dụng nền tảng điện toán đám mây Google Earth Engine (GEE) trong giám sát biến động đường bờ khu vực ĐBSCL [7]; nghiên cứu ứng dụng công nghệ viễn thám và GIS theo dõi biến động đường bờ và đánh giá tình hình sạt lở trên hai hệ thống sông Tiền và sông Hậu giai đoạn 1989-2017 [8]; nghiên cứu nguyên nhân gây gia tăng xói lở bờ sông ở ĐBSCL [9]; nghiên cứu ảnh hưởng của các yếu tố địa chất, thủy văn đến sạt lở bờ sông của các chi lưu như sông Cái Lân (Tiền Giang) [10], sông Cái Vừng (Đồng Tháp) [11], và sông Cái Sắn (Cần Thơ) [12]. Vì những lý do nêu trên, cần thiết phải có một nghiên cứu về các yếu tố ảnh hưởng đến sự xói lở của các cù lao trên sông. Trong nghiên cứu này, diễn biến đường bờ và diện tích bề mặt cù lao Long Khánh trên sông Tiền thuộc huyện Hồng Ngự, tỉnh Đồng Tháp sẽ được theo dõi bằng công nghệ phân tích ảnh viễn thám và các yếu tố ảnh hưởng đến sự thay đổi này sẽ được phân tích và đánh giá.

\section{Phương pháp nghiên cứu}

\subsection{Khu vục nghiên cứu}

Cù lao Long Khánh nằm ở phần thượng nguồn của sông Tiền thuộc huyện Hồng Ngự, tỉnh Đồng Tháp. Cù lao có diện tích khoảng 1960 ha (số liệu năm 2001), phân bố từ 105¹6' đến $105^{\circ} 22^{\prime}$ Đông và từ $10^{\circ} 46^{\prime}$ đến $10^{\circ} 50^{\prime}$ Bắc (Hình 1 ). Cù lao nằm trên dòng chảy chính của sông Tiền nên được phù sa bồi đắp rất màu mỡ và là nơi an cư của gần 18 nghìn nhân khẩu với các ngành nghề chính là trồng trọt và nuôi trồng, đánh bắt thủy sản. Với khí hậu trong lành cùng đặc sản đồng quê, du lịch sinh thái cũng là một ngành nghề đang phát triển trên cù lao trong những năm gần đây. Hàng năm, cù lao thu hút rất nhiều du khách trong và ngoài nước đến tham quan.

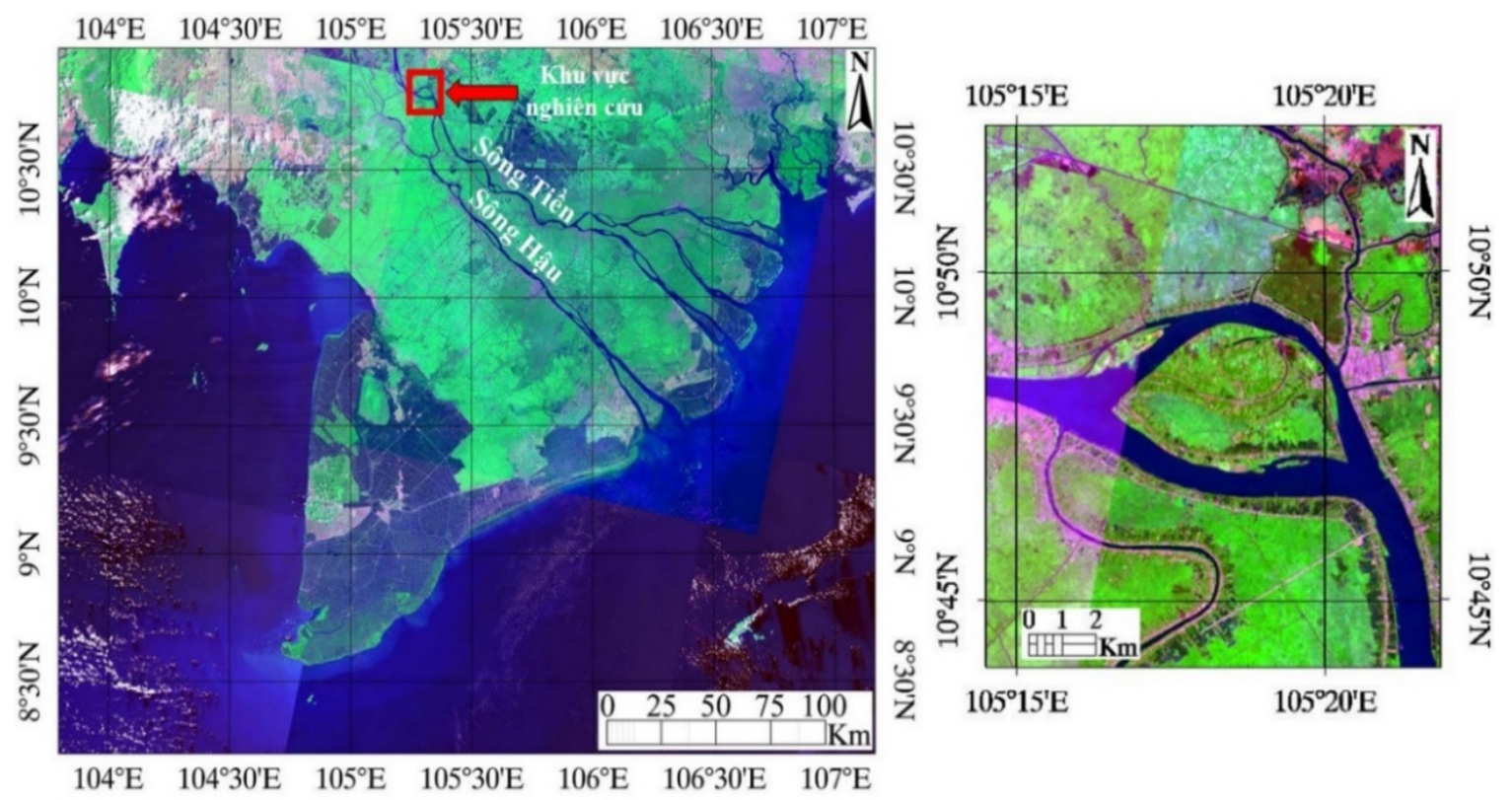

Hình 1. Khu vực nghiên cứu (tổ hợp SWIR2-NIR-G). 


\subsection{Số liệu thứ cấp}

Số liệu thứ cấp về tình hình sạt lở, địa hình lòng sông và thủy văn (lưu lượng, mực nước, hàm lượng bùn cát lơ lửng) được thu thập từ các nguồn như trình bày trong Bảng 1 .

Bảng 1. Số liệu và nguồn số liệu thứ cấp.

\begin{tabular}{clcl}
\hline STT & \multicolumn{1}{c}{ Tên số liệu } & Thòi gian & \multicolumn{1}{c}{ Nguồn } \\
\hline 1 & Số liệu sạt lở & 2020 & Chi cục Thủy lợi tỉnh Đồng Tháp \\
2 & Địa hình lòng sông & 2015,2019 & Chi cục Thủy lợi tỉnh Đồng Tháp \\
3 & Thủy văn (lưu lượng, mực nước, SSC) & $2000-2020$ & Trạm Khí tượng Thủy văn Tân Châu \\
\hline
\end{tabular}

\subsection{Giải đoán ảnh viễn thám}

Ảnh Landsat 5,8 và ảnh Sentinel-2 được thu thập để giải đoán đường bờ cù lao Long Khánh và tính toán diện tích bề mặt của cù lao cũng như sự dịch chuyển của cù lao trong các năm. Vì số liệu về thủy lực, thủy văn chỉ thu thập được trong khoảng thời gian từ năm 2000 đến năm 2021 nên các ảnh viễn thám cũng được thu thập trong khoảng thời gian này. Các ảnh Landsat có độ phân giải thấp nên không thể quan sát được diễn biến đường bờ theo từng năm mà được phân tích theo khoảng thời gian cách đều nhau 5 năm. Chi tiết thông số ảnh viễn thám được trình bày như trong Bảng 2 . Các ảnh được chọn trong các tháng có cao độ mực nước thấp trong năm [13] để hạn chế ảnh hưởng của dao động mực nước theo mùa.

Bảng 2. Dữ liệu ảnh viễn thám.

\begin{tabular}{cccccc}
\hline Thò̀ gian & Vệ tinh & Bộ cảm & $\begin{array}{c}\text { Độ phân giải } \\
(\mathbf{m})\end{array}$ & $\begin{array}{c}\text { Tỷ lệ mây } \\
(\mathbf{\%})\end{array}$ & Hệ tọa độ \\
\hline 26/03/2000 & Landsat 5 & TM & 30 & 13,00 & UTM \\
19/01/2005 & Landsat 5 & TM & 30 & 1,00 & UTM \\
$27 / 02 / 2010$ & Landsat 5 & TM & 30 & 23,00 & UTM \\
$21 / 04 / 2015$ & Landsat 8 & ETM+ & 30 & 0,87 & UTM \\
10/03/2020 & Landsat 8 & ETM+ & 30 & 9,28 & UTM \\
16/03/2020 & Sentinel-2 & MSI & 10 & 1,20 & UTM \\
15/01/2021 & Sentinel-2 & MSI & 10 & 0,28 & UTM \\
\hline
\end{tabular}

Chỉ số thực vật (NDVI) được sử dụng để phân tách vùng đất của cù lao với vùng nước bao bọc xung quanh cù lao theo các công thức sau:

Đối với ảnh Landsat 5 [14]:

$$
\text { NDVI }=\frac{\text { Kênh } 4-\text { Kênh } 3}{\text { Kênh } 4+\text { Kênh } 3}
$$

Trong đó kênh 4 là kênh cận hồng ngoại (NIR) và kênh 3 là kênh màu đỏ (RED).

Đối với ảnh Landsat 8 [15]:

$$
\text { NDVI }=\frac{\text { Kênh } 5-\text { Kênh } 4}{\text { Kênh } 5+\text { Kênh } 4}
$$

Trong đó kênh 5 là kênh cận hồng ngoại (NIR) và kênh 4 là kênh màu đỏ (RED).

Phần mềm ArcGIS được sử dụng để phân loại ảnh chỉ số thực vật thành vùng đất và nước sử dụng công cụ Reclassify. Dữ liệu raster vùng đất và nước được chuyển thành các Polygon và lưu dưới dạng tập tin .dwg. Kết quả giải đoán đường bờ không được hiệu chỉnh theo số liệu mực nước vì độ phân giải của ảnh Landsat thấp $(30 \mathrm{~m})$ nên ảnh hưởng của mực nước đến độ chính xác của kết quả giải đoán là không đáng kể [16]. Kết quả tính chỉ số thực vật NDVI được trình bày như trong Hình 2.

\subsection{Phân tích sụ thay đổi diện tích và vị trí của cù lao Long Khánh}

Để thuận tiện cho việc biểu diễn sự thay đổi vị trí của cù lao Long Khánh, một hệ tọa độ giả định được sử dụng với gốc $\mathrm{O}(0 ; 0)$ trùng với điểm có tọa độ $\left(10^{\circ} 46,75^{\prime} \mathrm{N} ; 105^{\circ} 16,03^{\prime} \mathrm{E}\right)$ 
trong hệ tọa độ địa lý toàn cầu WGS-84. Chi tiết việc chuyển đổi hệ tọa độ được thể hiện trên Hình 3.

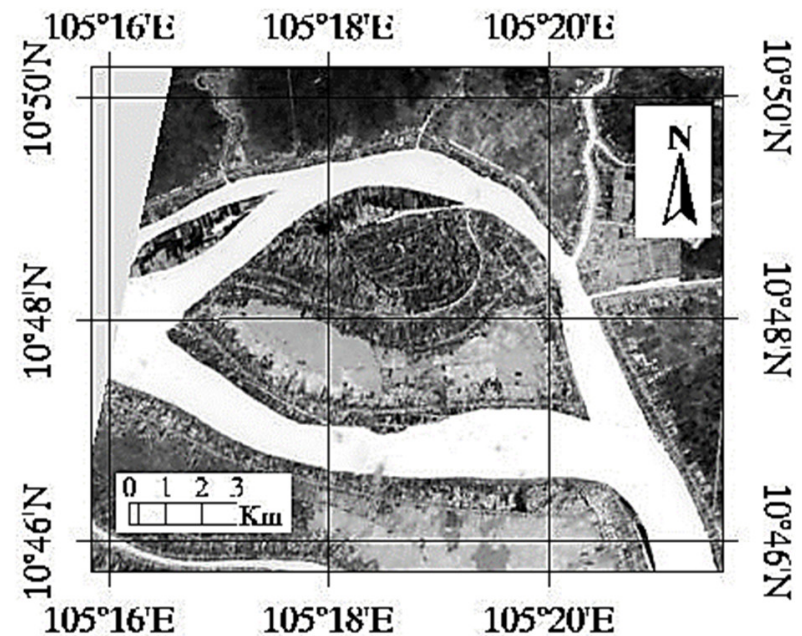

Hình 2. Chỉ số thực vật (NDVI) dùng để giải đoán đường bờ cù lao Long Khánh.

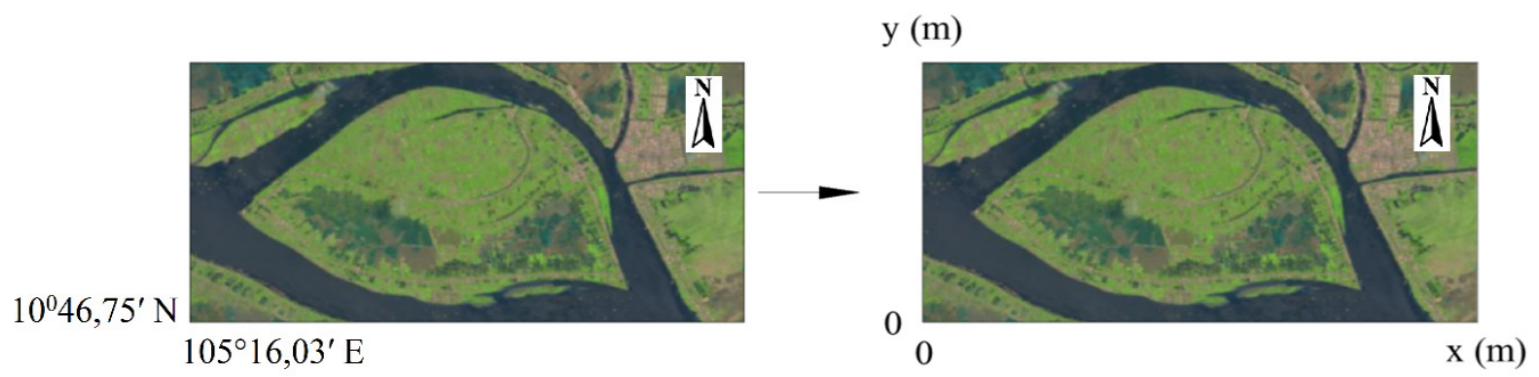

Hình 3. Chuyển đổi hệ trục tọa độ.

Thông thường, sự dịch chuyển của các cù lao trên sông là do xói lở ở đầu cù lao và bồi tụ ở phía đuôi cù lao. Độ dịch chuyển của cù lao Long Khánh được tính theo độ dịch chuyển của trọng tâm diện tích bề mặt của cù lao. Các đường bờ của cù lao qua các năm được lưu dưới dạng tập tin .dwg và diện tích cũng như trọng tâm của các diện tích này được tính toán trong phần mềm AutoCAD. Sự thay đổi diện tích bề mặt hoặc thay đổi vị trí của cù lao Long Khánh được dự báo thông qua mô hình hồi quy tuyến tính theo công thức:

$$
\mathrm{y}=\mathrm{a} \times \mathrm{t}+\mathrm{b}
$$

Trong đó y biểu diễn đại lượng cần tính toán (diện tích hoặc tọa độ trọng tâm cù lao Long Khánh); t là thời gian (năm), a là vận tốc thay đổi của diện tích hoặc vị trí của cù lao, và $\mathrm{b}$ là hằng số.

Sơ họa diện tích bề mặt của cù lao và trọng tâm của diện tích này được thể hiện trên Hình 4. Trong đó diện tích bề mặt cù lao là phần được tô xám và tọa độ trọng tâm diện tích bề mặt cù lao Long Khánh (trọng tâm cù lao) là ( $\left.\mathrm{x}_{\mathrm{c}}, \mathrm{y}_{\mathrm{c}}\right)$.

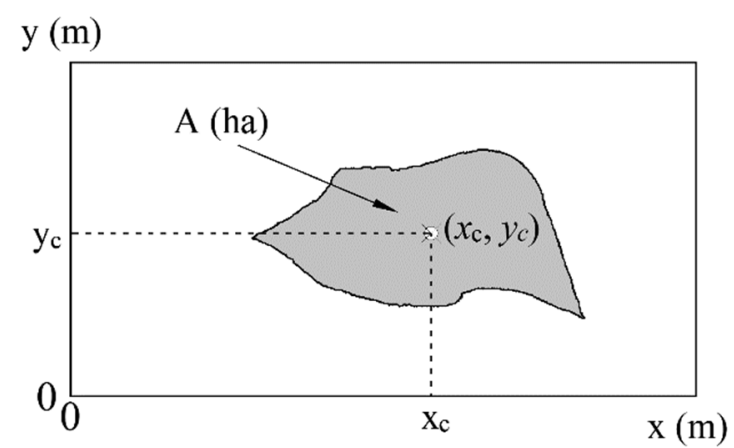

Hình 4. Sơ họa diện tích bề mặt và trọng tâm phần diện tích bề mặt cù lao Long Khánh. 


\subsection{Khảo sát vận tốc dòng chảy và phân tích mẫu bùn cát đáy}

Để có thể xác định ảnh hưởng của vận tốc dòng chảy đến diễn biến xói lở khu vực cù lao, vận tốc dòng chảy tại khu vực cù lao đã được đo đạc trong ngày 16/01/2021. Song song với việc đo đạc vận tốc dòng chảy, các mẫu bùn cát tại các vị trí sạt lở cũng được thu thập và phân tích thành phần hạt theo phương pháp rây sàng và tỷ trọng kế. Dựa vào kích thước hạt trung bình của mẫu bùn cát đáy $\left(\mathrm{d}_{50}\right)$ và chiều sâu cột nước tại vị trí lấy mẫu $(\mathrm{h})$, vận tốc không xói $\left(\mathrm{V}_{\mathrm{kx}}\right)$ của bùn cát cấu tạo bờ cù lao được xác định dựa vào TCVN 4118:2012 [17].

Thiết bị đo vận tốc dòng chảy MIDAS-ECM được sử dụng để đo vận tốc dòng chảy theo từng thủy trực. Thiết bị MIDAS-ECM được kết nối trực tiếp với máy tính và truyền tín hiệu liên tục về máy tính trong quá trình đo thông qua cáp kết nối dài $30 \mathrm{~m}$.

Thiết bị đo vận tốc dòng chảy, các vị trí đo vận tốc dòng chảy và lấy mẫu bùn cát được thể hiện trong Hình 5 . Bùn cát được lấy mẫu tại hai vị trí sát bờ trái cho mặt cắt $\mathrm{MC} 1-1$ và sát bờ phải cho mặt cắt $\mathrm{MC} 2-2$.

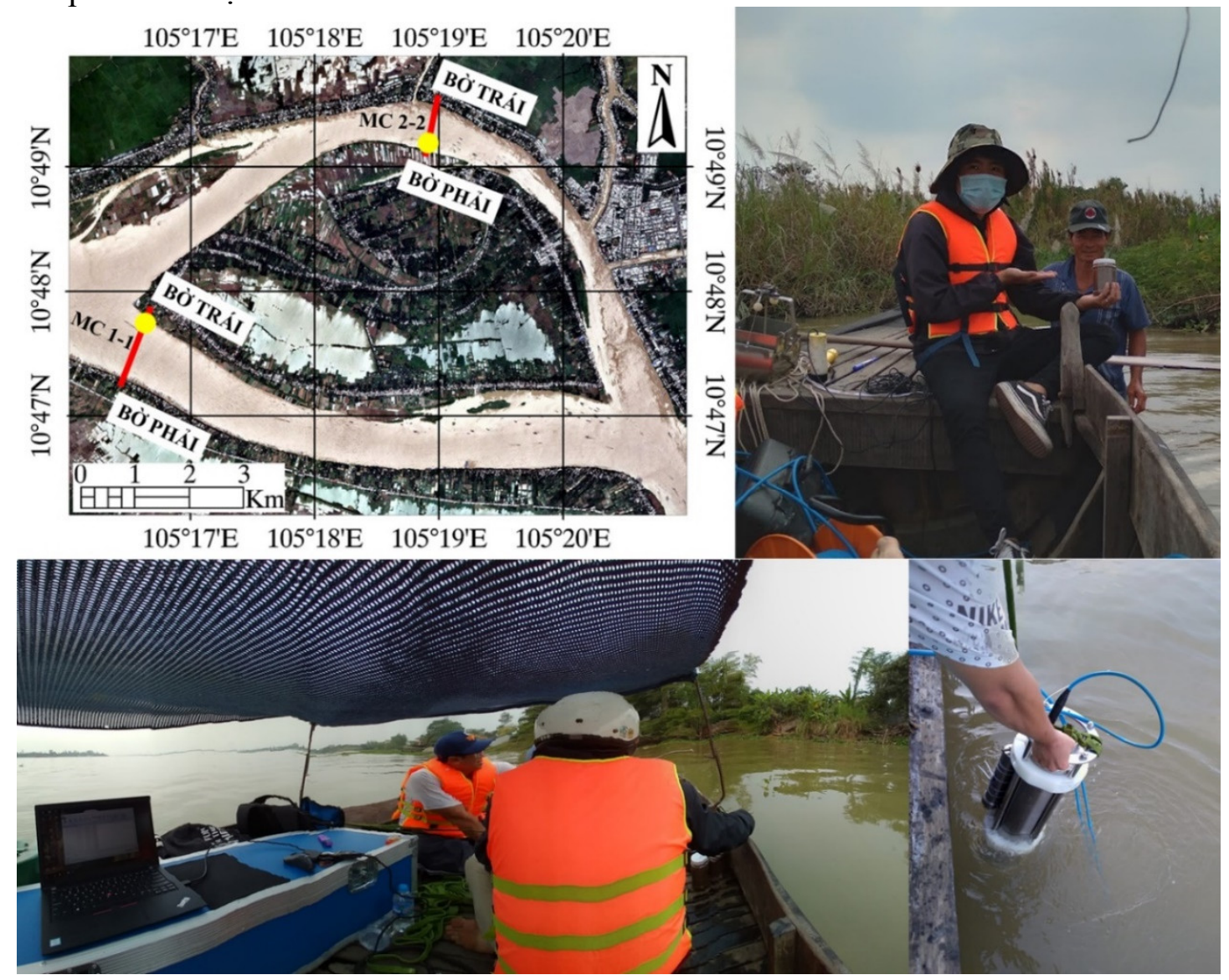

Hình 5. Đo vận tốc dòng chảy và lấy mẫu bùn cát.

\section{Kết quả và thảo luận}

\subsection{Biến động đường bờ của cù lao Long Khánh}

Sự biến động đường bờ cù lao Long Khánh giai đoạn 2000-2020 được biểu diễn trên Hình 6 với hệ trục tọa độ giả định như đã quy ước trong Hình 3 . Đường bờ các năm trước được chồng lên các ảnh trong các năm tiếp theo để có thể quan sát sự thay đổi vị trí đường bờ. Có thể nhận thấy, xói lở diễn ra rất mạnh tại đầu cù lao trong khi bồi tụ đang diễn ra tại phía bờ Bắc của cù lao. Diễn biến đường bờ cù lao Long Khánh phù hợp với kết quả khảo sát thực địa ngày $16 / 01 / 2021$. Thông qua vị trí đường bờ các năm 2000,2005 và 2015 , có thể nhận thấy sự phát triển của một doi cát ở phía Bắc cù lao. Giai đoạn 2000-2005, xói lở đã xảy ra ở đầu cù lao tuy nhiên mức độ xói lở không nghiêm trọng. Trong giai đoạn này, sự 
phát triển của doi cát ở phía Bắc cù lao có thể quan sát được một cách rất rõ ràng. Trong giai đoạn 2005-2010, xói lở ở đầu cù lao đã xảy ra với mức độ nghiêm trọng hơn. Doi cát ở phía Bắc cù lao vẫn phát triển với tốc độ như trong giai đoạn trước đó. Trong các năm 2015 và 2020, xói lở vẫn tiếp tục xảy ra ở đầu cù lao và vị trí của doi cát ở phía Bắc cù lao gần như đã ổn định.

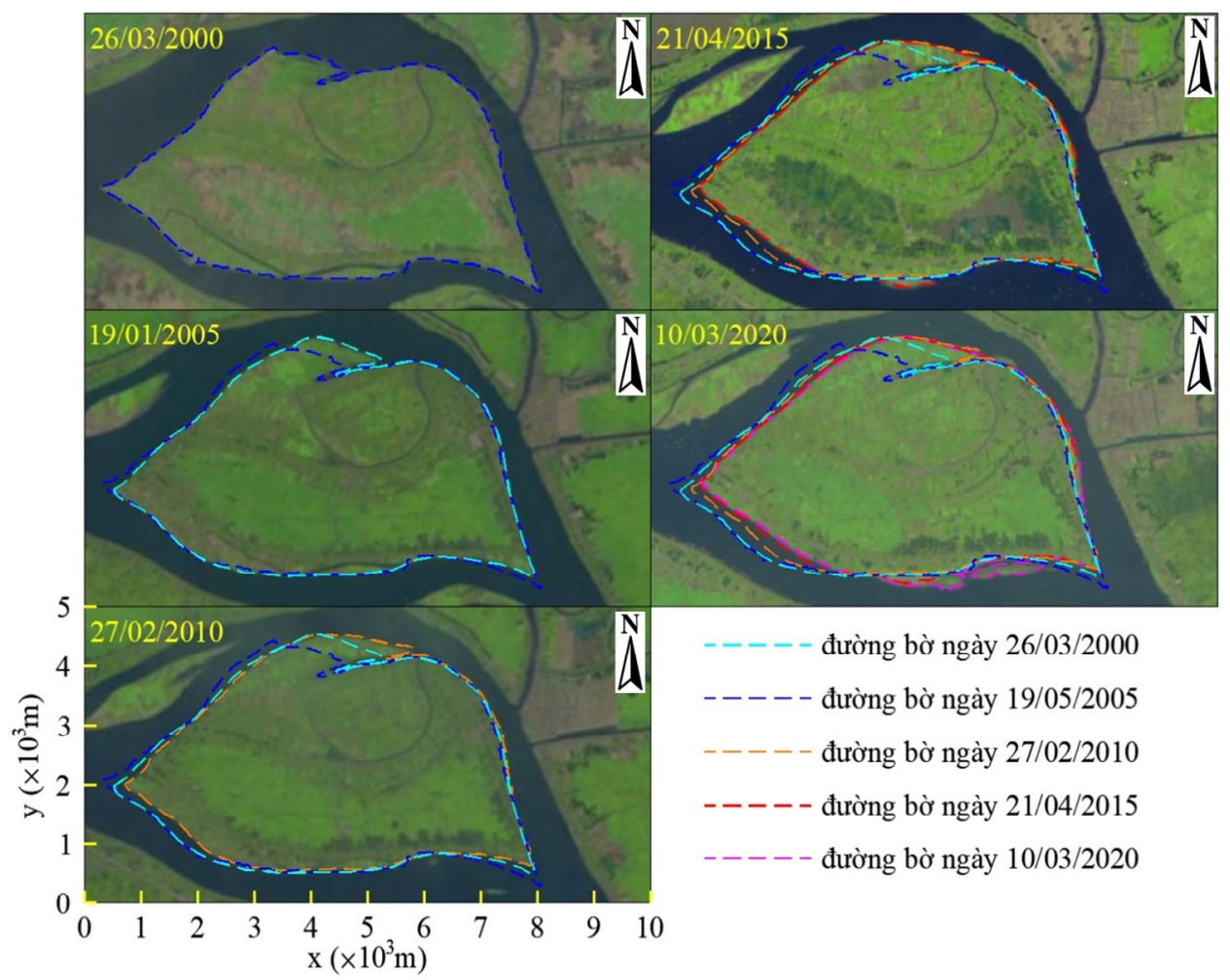

Hình 6. Biến động đường bờ cù lao Long Khánh.

Hiện trạng xói lở và bồi tụ của cù lao Long Khánh trong chuyến khảo sát ngày 16/01/2021 được thể hiện trên Hình 7. Tại các điểm $\mathrm{A}$ và $\mathrm{B}$ là điểm đầu và đuôi của cù lao, xói lở đang diễn ra rất nghiêm trọng với các vách xói lở thẳng đứng và cao đến $2,5 \mathrm{~m}$ tại phía đầu cù lao. Hiện tượng bồi tụ ở phía bờ bắc của cù lao cũng được thể hiện bằng một bãi bồi tại điểm $\mathrm{C}$ như trên Hình 7.

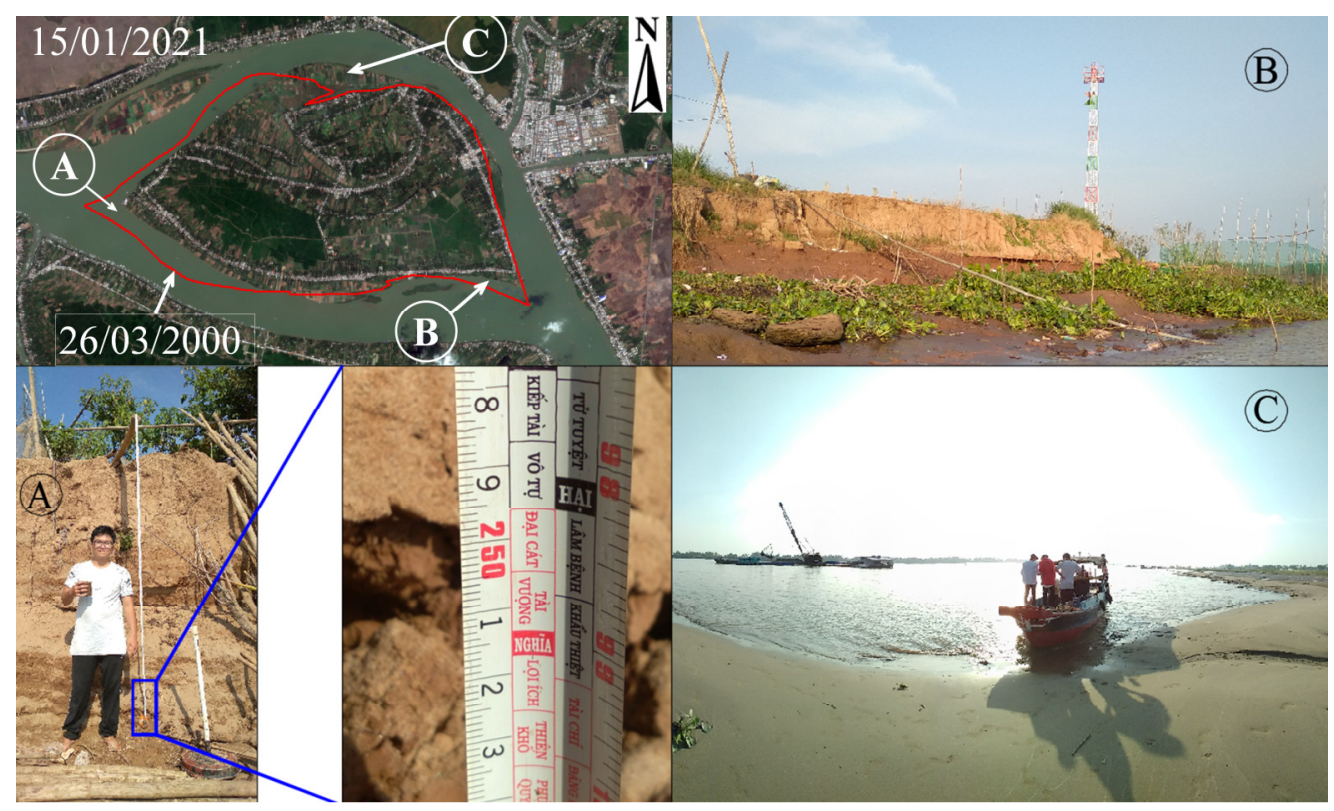

Hình 7. Hiện trạng xói lở và bồi tụ tại cù lao Long Khánh. 
Mặt cắt lòng dẫn tại vị trí MC 1-1 và MC 2-2 trong các năm 2015 và 2019 được trình bày trên Hình 8 . Có thể nhận thấy xói lở đang diễn ra tại bờ trái mặt cắt $\mathrm{MC} 1-1$ và bồi tụ đang diễn ra tại bờ phải của mặt cắt $\mathrm{MC} 2-2$. Điều này phù hợp với kết quả phân tích diễn biến đường bờ bằng ảnh viễn thám như đã trình bày ở trên.
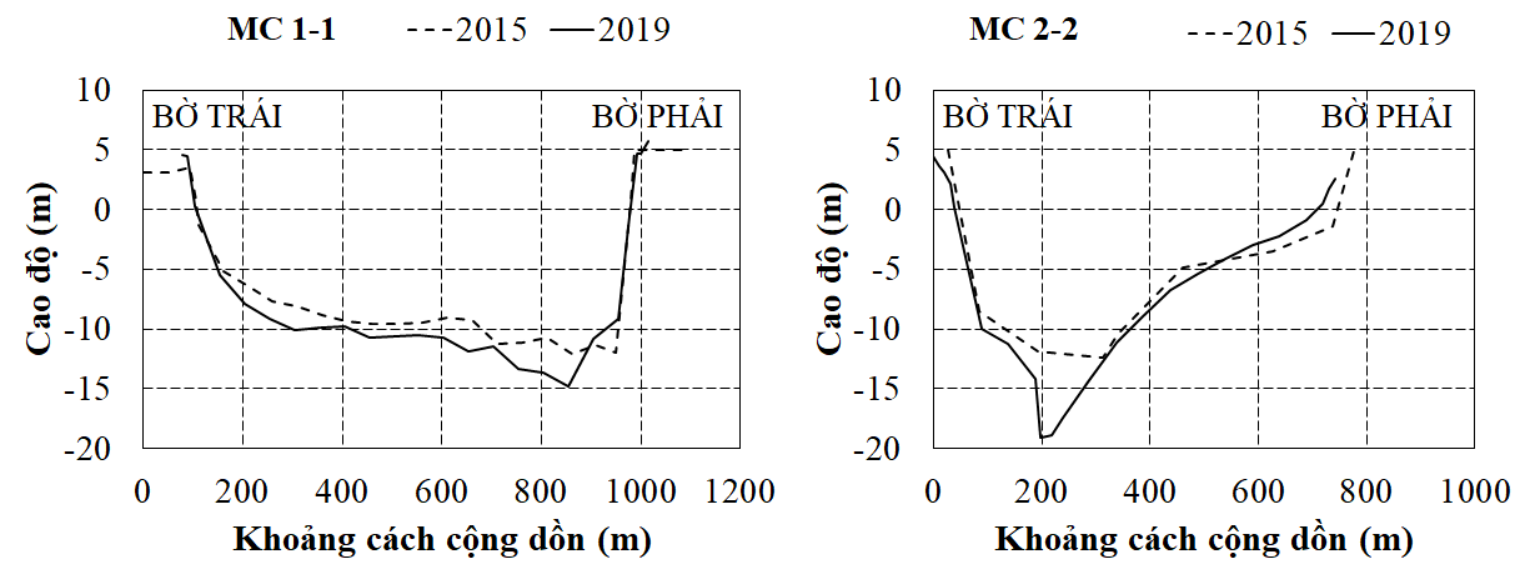

Hình 8. Mặt cắt sông các năm 2015 và 2019.

\subsection{Biến động diện tích và sụ dịch chuyển của cù lao Long Khánh}

Sự biến đổi diện tích cù lao Long Khánh được mô tả trên Hình 9. Diện tích của cù lao được tính bằng ảnh Sentinel-2 (độ phân giải $10 \mathrm{~m}$ ) cũng được sử dụng để so sánh với diện tích cù lao tính bằng ảnh Landsat 8 (độ phân giải $30 \mathrm{~m}$ ). Cụ thể, ảnh Sentinel-2 được sử dụng là ảnh chụp ngày 16/03/2020 và chỉ cách 6 ngày so với ảnh Landsat 8 được chụp vào ngày $10 / 03 / 2020$. Có thể thấy diện tích của cù lao ngày $10 / 03 / 2020$ được tính bằng ảnh Landsat 8 (1974,59 ha) xấp xỉ diện tích của cù lao ngày 16/03/2020 được tính bằng ảnh Sentinel-2 (1977,25 ha). Như vậy việc sử dụng ảnh Landsat có độ phân giải $30 \mathrm{~m}$ để tính toán diện tích cù lao là phù hợp.

Có thể thấy diện tích cù lao có xu hướng giảm từ năm 2000 đến 2020 với vận tốc trung bình là 2,92 ha/năm. Theo phân tích hồi quy tuyến tính [18], diện tích của cù lao giảm theo quy luật:

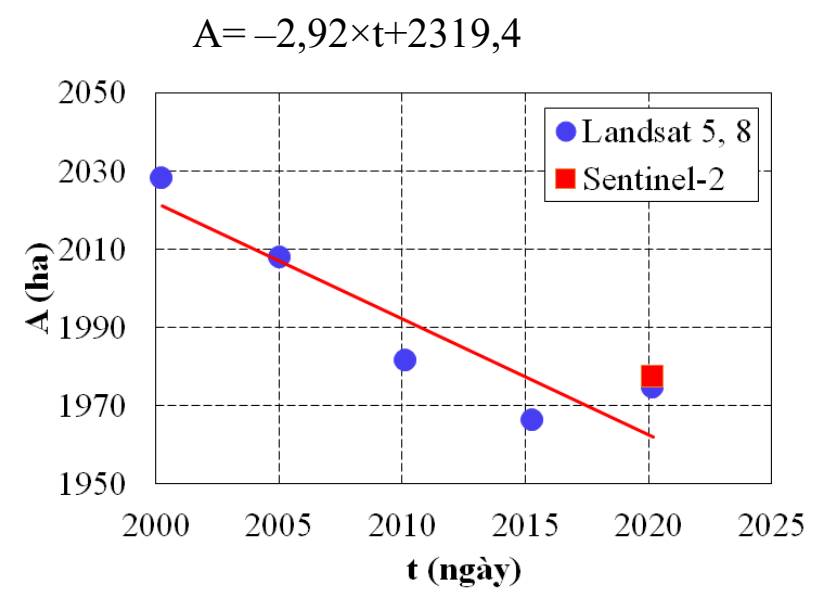

Hình 9. Thay đổi diện tích cù lao Long Khánh.

Tọa độ trọng tâm $\left(\mathrm{x}_{\mathrm{c}} ; \mathrm{y}_{\mathrm{c}}\right)$ của cù lao Long Khánh trong giai đoạn 2000-2020 được thể hiện trên Hình 10. Trong đó, $\mathrm{x}_{\mathrm{c}}$ thể hiện tọa độ trọng tâm của cù lao theo hướng dòng chảy từ Tây sang Đông và $\mathrm{y}_{\mathrm{c}}$ thể hiện tọa độ trọng tâm của cù lao theo hướng Nam-Bắc. Theo phương $\mathrm{x}$, có thể thấy cù lao đang dịch chuyển về phía hạ lưu với vận tốc trung bình là 12,92 $\mathrm{m} /$ năm. Theo phương y (hướng Nam-Bắc), trọng tâm cù lao có xu hướng dịch chuyển lên phía Bắc với vận tốc trung bình là $8,61 \mathrm{~m} / \mathrm{năm}$ trong giai đoạn $2000-2010$ và có xu hướng di 
chuyển xuống phía Nam với vận tốc trung bình là 1,68 m/năm trong giai đoạn 2010-2020. Điều này có thể giải thích bằng sự hình thành một doi cát phía Bắc cù lao (Hình 6). Trong giai đoạn 2000-2010, doi cát có xu hướng phát triển lên phía Bắc nên kéo trọng tâm của cù lao lên phía Bắc. Tuy nhiên, doi cát sau đó bị kéo dài ra và có xu hướng phát triển về phía đuôi cù lao nên đã làm cho trọng tâm của cù lao dịch chuyển xuống phía Nam.
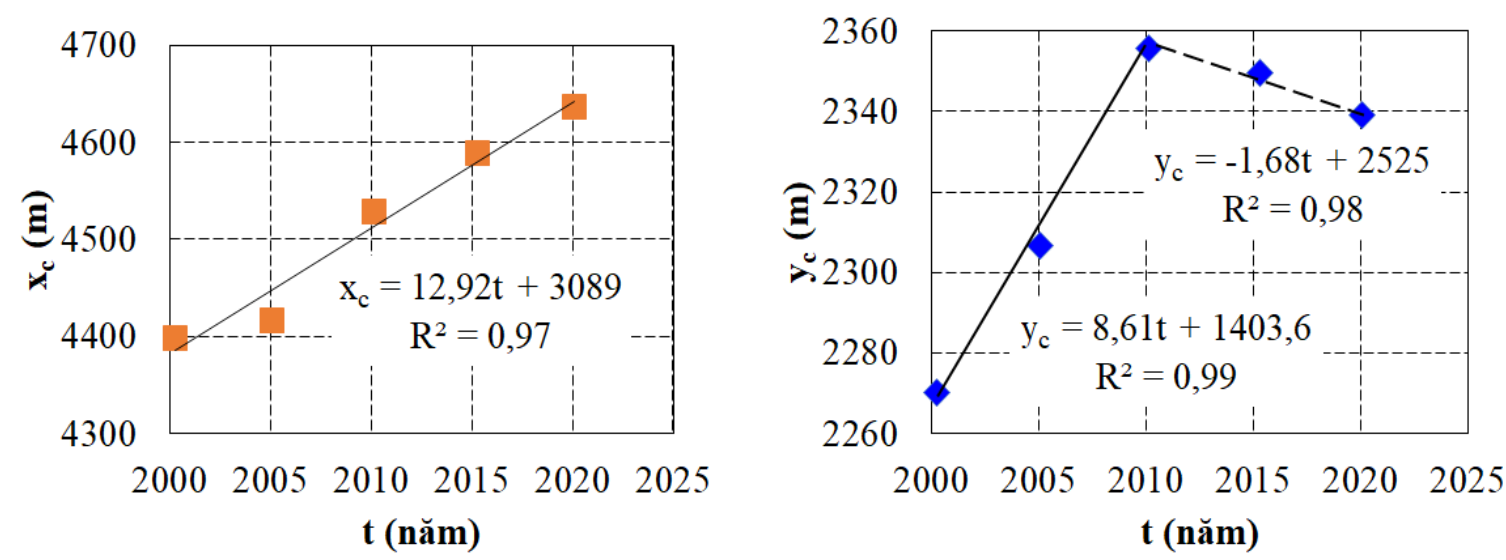

Hình 10. Sự dịch chuyển của cù lao Long Khánh.

3.3. Anh hương của luu luợng dòng chảy $(Q)$ và hàm luợng bùn cát lơ lủng (SSC) đến sụ thay đổi diện tích cù lao Long Khánh

Số liệu lưu lượng dòng chảy $(\mathrm{Q})$ và hàm lượng bùn cát lơ lửng (SSC) được sử dụng để tính toán tương quan của các đại lượng này đến sự thay đổi diện tích bề mặt cù lao $(\mathrm{A})$. Các số liệu được trình bày trong Bảng 3 .

Bảng 3. Số liệu $\mathrm{A}(\mathrm{ha}), \mathrm{Q}\left(\mathrm{m}^{3} / \mathrm{s}\right)$ và $\mathrm{SSC}\left(\mathrm{g} / \mathrm{m}^{3}\right)$.

\begin{tabular}{|c|c|c|c|}
\hline Năm & A (ha) & $\mathbf{Q}\left(\mathrm{m}^{3} / \mathrm{s}\right)$ & $\operatorname{SSC}\left(\mathrm{g} / \mathrm{m}^{3}\right)$ \\
\hline 2000 & $2.028,01$ & 12.087 & 123 \\
\hline 2005 & $2.007,71$ & 9.435 & 70 \\
\hline 2010 & $1.981,36$ & 11.507 & 90 \\
\hline 2015 & $1.966,22$ & 7.971 & 57 \\
\hline 2020 & $1.974,59$ & 9.950 & 41 \\
\hline
\end{tabular}

Tương quan giữ các giá trị $\mathrm{Q}, \mathrm{SSC}$ và $\mathrm{A}$ qua các năm cũng được thể hiện trên Hình 11 . Có thể nhận thấy sự biến thiên của $\mathrm{Q}, \mathrm{SSC}$ có tương quan tốt với sự biến thiên của $\mathrm{A}$ qua các năm. Ngoại trừ giai đoạn 2005-2010, sự biến thiên của Q, SSC là tăng trong khi A giảm.
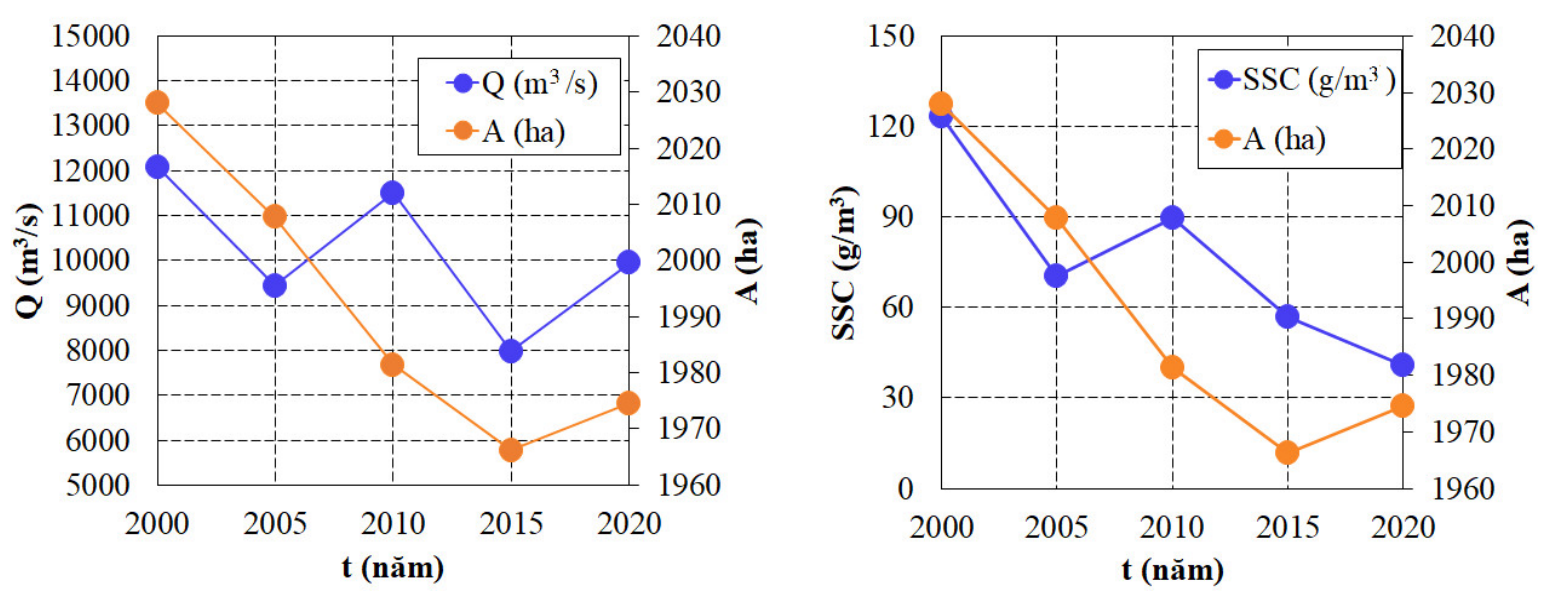

Hình 11. Tương quan giữa $\mathrm{Q}\left(\mathrm{m}^{3} / \mathrm{s}\right)$ với $\mathrm{A}(\mathrm{ha})$ và giữa $\mathrm{SSC}\left(\mathrm{g} / \mathrm{m}^{3}\right)$ với $\mathrm{A}(\mathrm{ha})$. 


\subsection{Vận tốc dòng chảy}

Sự phân bố của vận tốc dòng chảy trên các mặt cắt $\mathrm{MC} 1-1$ và $\mathrm{MC} 2-2$ được vẽ từ giá trị vận tốc thực đo tại các thủy trực và các giá trị nội suy như trên Hình 12 . Có thể nhận thấy tại $\mathrm{MC} 1-1$, vận tốc dòng chảy phân bố tương đối cân xứng trên toàn bộ mặt cắt sông vì đây là đoạn sông thẳng. Tại các vị trí gần bờ, vận tốc dòng chảy có giá trị từ $0,15 \mathrm{~m} / \mathrm{s}$ đến 0,32 $\mathrm{m} / \mathrm{s}$. Tại mặt cắt MC 2-2, vận tốc dòng chảy phân bố lệch về phía bờ trái vì đây là đoạn sông cong (vận tốc tại bờ phải (bờ cù lao Long Khánh) có giá trị từ $0,15 \mathrm{~m} / \mathrm{s}$ đến $0,23 \mathrm{~m} / \mathrm{s}$ ).

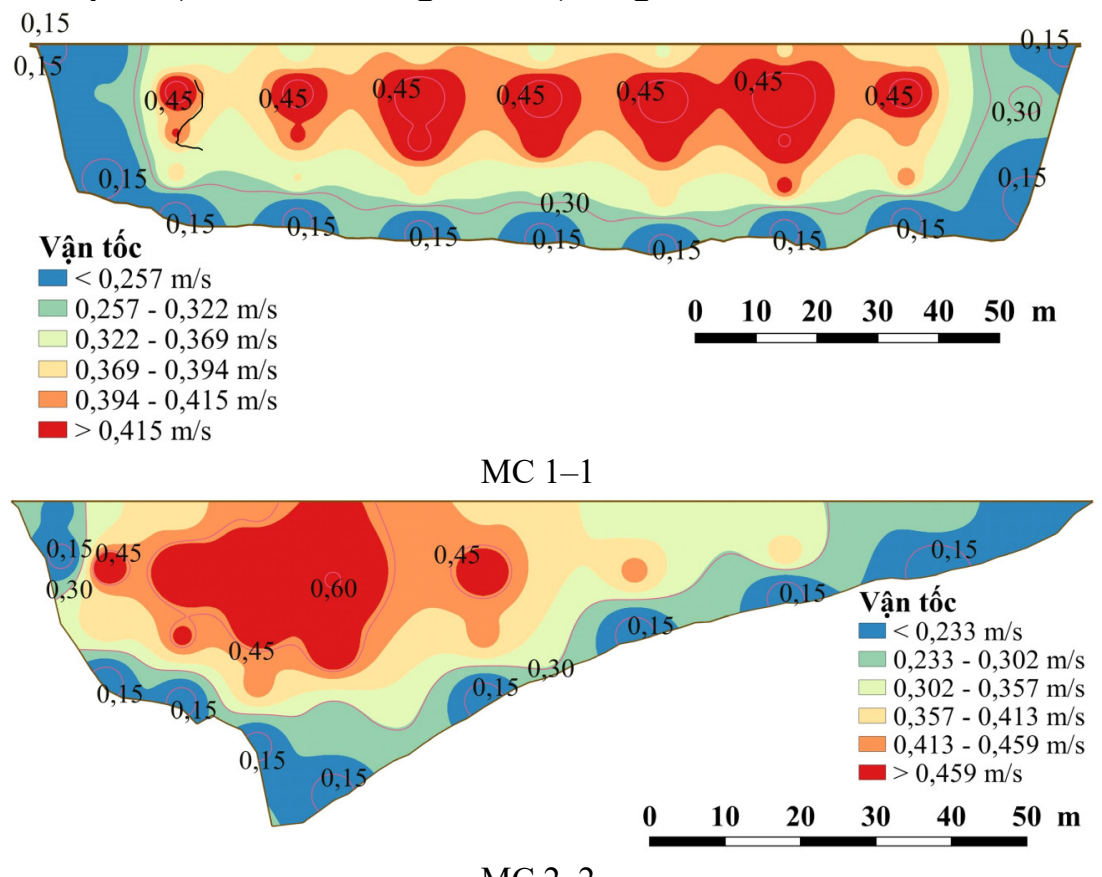

MC 2-2

Hình 12. Phân bố vận tốc dòng chảy tại các mặt cắt.

\subsection{Phân tích thành phần hạt bùn cát đáy sông}

Hình 13 thể hiện đường cong cấp phối hạt của mẫu bùn cát đáy được lấy mẫu sát bờ cù lao Long Khánh trên các mặt cắt $\mathrm{MC} 1-1$ và $\mathrm{MC} 2-2$. Từ biểu đồ đường cong cấp phối hạt, có thể xác định được kích thước hạt trung bình $\left(\mathrm{d}_{50}\right)$ của mẫu bùn cát đáy tại $\mathrm{MC} 1-1$ và $\mathrm{MC}$ $2-2$ lần lượt là $0,01 \mathrm{~mm}$ và $0,15 \mathrm{~mm}$.

$\bullet \mathrm{MC} 1-1 \star \mathrm{MC} 2-2$

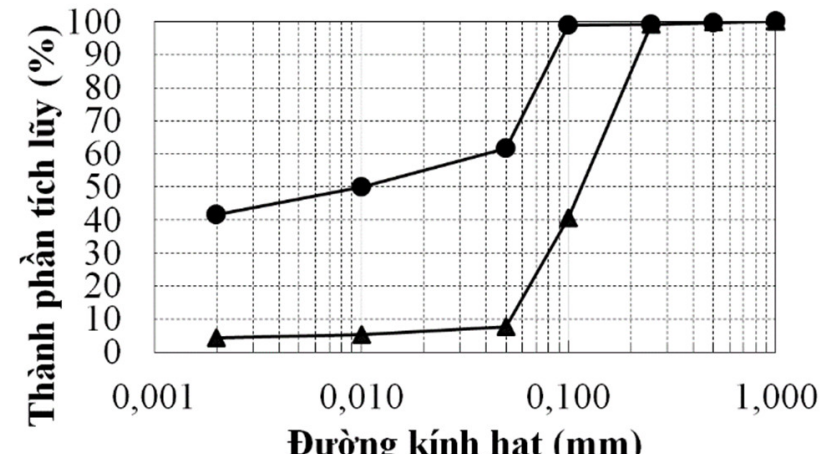

Đường kính hạt $(\mathbf{m m})$

Hình 13. Đường cong cấp phối hạt bùn cát tại các vị trí sát bờ cù lao trên $\mathrm{MC} 1-1$ và $\mathrm{MC} 2-2$.

Dựa vào giá trị kích thước hạt trung bình $\left(\mathrm{d}_{50}\right)$ của bùn cát đáy sông và chiều sâu cột nước trong sông $(\mathrm{h}>3 \mathrm{~m})$, ta xác định được vận tốc không xói của bùn cát theo TCVN 4118:2012 [17] như được trình bày trong Bảng 4. Có thể thấy, tại vị trí bờ trái mặt cắt $\mathrm{MC}$ $1-1$, giá trị vận tốc thực đo lớn hơn giá trị vận tốc không xói của bùn cát. Như vậy, tại vị trí 
này dòng chảy là nguyên nhân gây xói lở bờ sông. Tuy nhiên, tại mặt cắt $\mathrm{MC} 2-2$, vận tốc thực đo nhỏ hơn vận tốc không xói của bùn cát đáy nên dòng chảy không có khả năng gây ra xói lở tại khu vực này. Kết quả này phù hợp với kết quả phân tích diễn biến thay đổi đường bờ cù lao như trong Hình 6.

Bảng 4. Giá trị $\mathrm{d}_{50}, \mathrm{~V}_{\mathrm{kx}}$ và $\mathrm{V}$ tại các vị trí dọc bờ cù lao Long Khánh.

\begin{tabular}{cccc}
\hline Mặt cắt & $\mathbf{d}_{\mathbf{5 0}}(\mathbf{m m})$ & $\mathbf{V}_{\mathbf{k x}}(\mathbf{m} / \mathbf{s})$ & $\mathbf{V}(\mathbf{m} / \mathbf{s})$ \\
\hline $1-1$ & 0,01 & $0,19-0,26$ & $0,15-0,32$ \\
$2-2$ & 0,15 & $0,26-0,40$ & $0,15-0,23$ \\
\hline
\end{tabular}

\section{Kết luận}

Xói lở đang xảy ra nghiệm trọng tại đầu cù lao Long Khánh với các vách xói lở lên đến $2,5 \mathrm{~m}$ và bồi tụ đang diễn ra tại phía Bắc cù lao với sự xuất hiện của một doi cát tại vị trí này. Kết quả phân tích thay đổi hình dạng mặt cắt sông trong hai năm 2015 và 2019 cũng cho thấy sự xói lở tại đầu cù lao và bồi tụ tại phía Bắc của cù lao. Diện tích bề mặt của cù lao đang giảm dần từ năm 2000 đến năm 2020 với vận tốc trung bình là 2,92 ha/năm. Trong giai đoạn 2000-2020, cù lao có xu hướng dịch chuyển theo dòng chảy với vận tốc trung bình là 12,92 $\mathrm{m} / \mathrm{năm}$. Theo phương ngang sông, cù lao dịch chuyển lên phía Bắc và xuống phía Nam với vận tốc trung bình lần lượt là $8,61 \mathrm{~m} /$ năm (giai đoạn $2000-2010$ ) và và $1,68 \mathrm{~m} / \mathrm{năm}$ (giai đoạn 2010-2020).

Thay đổi của lưu lượng dòng chảy $(\mathrm{Q})$ và hàm lượng bùn cát lơ lửng $(\mathrm{SSC})$ có tương quan tốt với sự thay đổi diện tích cù lao $(\mathrm{A})$. So sánh kết quả vận tốc thực đo $(\mathrm{V})$ với vận tốc không xói $\left(\mathrm{V}_{\mathrm{kx}}\right)$ của bùn cát đáy cho thấy vận tốc dòng chảy đang gây ra xói lở tại đầu cù lao. Tại phía Bắc cù lao, vận tốc dòng chảy nhỏ hơn vận tốc không xói của bùn cát đáy nên vận tốc dòng chảy không gây ra xói lở khu vực này. Các số liệu đo vận tốc dòng chảy trong nghiên cứu này chỉ thực hiện trong thời gian ngắn (ngày 16/01/2021); do đó cần được tiếp tục đo đạc đặc biệt trong mùa lũ để có thể đánh giá chính xác ảnh hưởng của vận tốc dòng chảy đến xói lở cù lao.

Đóng góp của tác giả: Xây dựng ý tưởng nghiên cứu: L.H.T., D.V.D., T.V.T.; Lựa chọn phương pháp nghiên cứu: L.H.T., D.V.D., T.V.T.; Xử lý số liệu: L.H.T., D.V.D., L.H.T., N.T.A.; Lấy mẫu: L.H.T., D.V.D., T.V.T.; Phân tích mẫu: T.V.T., D.V.D., L.H.T.; Viết bản thảo bài báo: L.H.T., D.V.D., H.T.C.H.; Chỉnh sửa bài báo: D.V.D., H.V.T.M., T.V.T.

Lời cam đoan: Tập thể tác giả cam đoan bài báo này là công trình nghiên cứu của tập thể tác giả, chưa được công bố ở đâu, không được sao chép từ những nghiên cứu trước đây; không có sự tranh chấp lợi ích trong nhóm tác giả.

\section{Tài liệu tham khảo}

1. Anthony, E.J.; Brunier, G.; Besset, M.; Goichot, M.; Dussouillez, P.; and Lap, N.V. Linking rapid erosion of the Mekong River delta to human activities. Sci. Rep. 2015, 5(1), $1-12$.

2. Dũng, N.V. Nghiên cứu dự báo sạt lở tại khu vực cù lao Long Khánh trên sông Tiền và đề xuất các giải pháp bảo vệ. Luận văn thạc sĩ, 2014, tr.124.

3. Wyrick, J.R.; and Klingeman, P.C. Proposed fluvial island classification scheme and its use for river restoration. River Res. Appl. 2011, 27, 814-825.

4. Sadek, N. Island development impacts on the Nile River morphology. Ain Shams Eng. J. 2013, 4, 25-41.

5. Sun, J.; Ding, L.; Li, J.; Qian, H.; Huang, M.; and Xu, N. Monitoring Temporal Change of River Islands in the Yangtze River by Remotely Sensed Data. Water 2018, 10, 1484.

6. Shi, H.; Gao, C.; Dong, C.; Xia, C.; and Xu, G. Variation of River Islands around a 
Large City along the Yangtze River from Satellite Remote Sensing Images. Sensors 2017, 17(10), 2213.

7. Long, V.H.; Giang, N.V.; Hoành, T.P.; và Hòa, P.V. Úng dụng công nghệ xử lí ảnh viễn thám trên nền tảng điện toán đám mây (GEE) trong theo dõi biến động đường bờ sông - thí điểm tại sông Cửu Long. Tạp chi khoa họ Tụ nhiên và Công nghẹ Truờng Đại học Su phạm Thành phố Hồ Chí Minh 2019, 16(S6), 38-49.

8. Điệp, N.T.H.; Minh, V.Q.; Trường, P.N.; Thành, L.K.; và Vinh, L.T.Q. Diễn tiến tình hình sạt lở ven bờ sông Tiền và sông Hậu, vùng đồng bằng sông Cửu Long. Tạp chi Khoa học Trường Đại học Cần Tho 2019, 55, 125-133.

9. Hoài, H.C.; Bảy, N.T.; Khôi, Đ.N.; và Nga, T.N.Q. Phân tích nguyên nhân gây gia tăng xói lở bờ sông ở Đồng bằng sông Cửu Long. Tạp chi Khí tượng Thủy văn 2019 , 7, 42-50.

10. Trí, L.H.; Thành, Đ.T.; Linh, L.T.C.; Thịnh, L.H.; và Tỷ, T.V. Phân tích ảnh hưởng của các yếu tố đến ổn định bờ sông: Trường hợp nghiên cứu tại sông Cái Lân, huyện Cái Bè, tỉnh Tiền Giang. Tạp chí Nông nghiệp \& Phát triển Nông thôn 2021, 15, 25 34.

11. Bằng, L.H.; Thịnh, L.V.; Trí, L.H.; Duy, Đ.V.; Tỷ, T.V.; và Minh, H.V.T. Nghiên cứu ảnh hưởng của các yếu tố địa chất, thủy văn đến ổn định bờ sông Cái Vừng, huyện Hồng Ngự, tỉnh Đồng Tháp. Tạp chi Khí tượng Thủy văn 2021, 731, 16-25.

12. Lộc, N.Đ.; Linh, L.T.C.; Minh, H.V.T.; Luận, T.C.; Tho, N.V.; Hưng, V.V.; và Tỷ, T.V. Xác định nguyên nhân sạt lở bờ sông theo phương pháp khảo sát thực địa: nghiên cứu tại sông Cái Sắn, thành phố Cần Thơ. Tạp chí Xây dựng 2020, 7, 146151.

13. Binh, D.V.; Kantoush, S.A.; Sumi, T.; Mai, N.T.P.; Ngoc, T.A.; Trung, L.V.; and An, T.D. Effects of riverbed incision on the hydrology of the Vietnamese Mekong Delta. Hydrol. Processes 2021, 35(2), e14030.

14. Sayler, K. Landsat 4-7 Collection 1 (C1) Surface Reflectance (LEDAPS) Product Guide. 2020, pp. 39.

15. Sayler, K. Landsat 8 Collection 1 (C1) Land Surface Reflectance Code (LaSRC) Product Guide. 2020, pp. 38.

16. Quỳnh, H.N.N.; Khôi, Đ.N.; Hoài, H.C.; và Bảy, N.T. Úng dụng viễn thám và GIS đánh giá biến động đường bờ sông Tiền và sông Hậu. Tạp chi Khi tương Thủy văn 2018, 6, 12-22.

17. Bộ Khoa học và Công nghệ. TCVN 4118 : 2012 Công trình thủy lợi - Hệ thống tưới tiêu - Yêu cầu thiết kế. 2012.

18. Schober, P.; Boer, C.; and Schwarte, L.A. Correlation Coefficients: Appropriate Use and Interpretation. Anesth. Analg. 2018, 126(5), 1763-1768.

\title{
Analyzing the factors affecting the surface area change of Long Khanh island in Hong Ngu district, Dong Thap province
}

\author{
Le Hoang Tu${ }^{1}$, Dinh Van Duy ${ }^{2 *}$, Le Hai Tri², Nguyen Thai An², Huynh Vuong Thu \\ Minh $^{3}$, Huynh Thi Cam Hong ${ }^{2}$, Tran Van Ty ${ }^{2}$ \\ ${ }^{1}$ Department of Agriculture and Rural Development of Đồng Tháp province; \\ tucctldt@gmail.com. \\ ${ }^{2}$ College of Engineering Technology, Can Tho University; dvduy@ctu.edu.vn; \\ lehaitri@gmail.com; htchong@ctu.edu.vn; anb1908310@student.ctu.edu.vn; \\ tvty@ctu.edu.vn. \\ ${ }^{3}$ College of Environment and Natural Resources, Can Tho University; \\ hvtminh@ctu.edu.vn.
}


Abstract: The objective of this study is to use satellite images to analyze the temporal variation of the surface area (A) and location of Long Khanh Island. Landsat images were used to analyze the riverbank line and area changes of Long Khanh island from 2000 to 2020. Secondary data such as discharge (Q) and Suspended Sediment Concentration (SSC) are collected to observe the correlation between Q, SSC, and A. Flow velocity (V) was also measured to compare with the allowed non-erosion velocity $\left(\mathrm{V}_{\mathrm{kx}}\right)$ of bed sediment. The analysis results show that Q, SSC, and V are factors causing the changes in the island's shoreline and area. Specifically, the flow velocity is causing erosion at the head of the island. To date, few studies on the correlation between river island's area changes and hydrological and hydraulic conditions of the rivers in the Vietnamese Mekong Delta (VMD) have been conducted. Therefore, the results from this study will contribute to some extent of the relationship between river island area (A) and its influencing factors such as Q, SSC, and V in the VMD.

Keywords: Long Khanh Island; Riverbank line; Landsat image; Suspended sediment; Flow velocity. 